\title{
Induction of SPARC by VEGF in Human Vascular Endothelial Cells
}

\author{
Yasumasa Kato, ${ }^{* \dagger, \ddagger, 1}$ Jean-Marc Lewalle,* Yuh Baba,† Mamoru Tsukuda.† Naoki Sakai,§ Masaya Baba,§ \\ Kazuki Kobayashi,§ Shinri Koshika,ł Yoji Nagashima," Francis Frankenne,* Agnés Noël,* Jean-Michel \\ Foidart,* and Ryu-Ichiro Hata $\|$ \\ *Laboratory of Tumor and Developmental Biology, University of Liège Faculty of Medicine, B-4000 Liège, Belgium; †Department of \\ Otolaryngology, §Department of Urology, and " Department of Pathology, Yokohama City University School of Medicine, Yokohama 236- \\ 0004, Japan; and $\ddagger$ Department of Biochemistry and Molecular Biology, ||Division of Gene Regulation, Bioventure Research Center, \\ Kanagawa Dental College, Yokosuka 238-8580, Japan
}

\begin{abstract}
SPARC/osteonectin/BM-40 is a matricellular protein that is thought to be involved in angiogenesis and endothelial barrier function. Previously, we have detected high levels of SPARC expression in endothelial cells (ECs) adjacent to carcinomas of kidney and tongue. Although SPARC-derived peptide showed an angiogenic effect, intact SPARC itself inhibited the mitogenic activity of vascular endothelial growth factor (VEGF) for ECs by the inhibiting phosphorylation of flt-1 (VEGF receptor 1) and subsequent ERK activation. Thus, the role of SPARC in tumor angiogenesis, stimulation or inhibition, is still unclear. To clarify the role of SPARC in tumor growth and progression, we determined the effect of VEGF on the expression of SPARC in human microvascular EC line, HMEC-1, and human umbilical vein ECs. VEGF increased the levels of SPARC protein and steady-state levels of SPARC mRNA in serum-starved HMEC-1 cells. Inhibitors (SB202190 and SB203580) of p38, a mitogen-activated protein (MAP) kinase, attenuated VEGF-stimulated SPARC production in ECs. Since intact SPARC inhibits phosphorylation ERK MAP kinase in VEGF signaling, it was suggested that SPARC plays a dual role in the VEGF functions, tumor angiogenesis, and extravasation of tumors mediated by the increased permeability of endothelial barrier function.
\end{abstract}

Key Words: endothelial cells; SPARC/osteonectin/ BM-40; angiogenesis; VEGF; MAP kinase.

SPARC/osteonectin/BM-40 is a matricellular protein with a molecular mass of $43 \mathrm{kDa}$ and is known to have a variety of functions. For example, SPARC inhibits the formation of focal adhesion (1) and the production of basement membrane components $(2,3)$, increases the permeability of endothelial barriers (4), and induces the production and activation of matrix metallo-proteinases $(5,6)$. In addition, SPARC promotes the motility of tumor cells such as renal cell carcinoma (7) and malignant prostatic cancer cell lines (8). A high level of SPARC expression has been frequently observed in variety of malignant tumors (9-15), and its fragment, the (K)GHK motif, induces angiogenesis in vivo (16). These data suggest that SPARC contributes tumor progression.

Angiogenesis is an essential process for tumor growth, and an increase in it raises the risk of tumor metastasis incidence. Since vascular endothelial growth factor (VEGF), which is a potent angiogenic factor, effectively stimulates tube/cord formation by vascular endothelial cells (ECs), a high productive ability for VEGF secretion is thought to be an important malignant phenotype of tumors. Paley et al. (17) determined the localization of VEGF and SPARC in clinical specimens of malignant ovarian carcinomas, and showed that VEGF and SPARC were expressed in the tumor cells and adjacent stromal cells, respectively. We also detected SPARC expression in ECs adjacent to carcinomas of the kidney (18) and tongue (Kato et al. unpublished data) which were producing VEGF. Although SPARC-derived (K)GHK peptide induces angiogenesis in vivo, SPARC was reported to inhibit the mitogenic activity of VEGF toward microvascular ECs by reducing the level of tyrosine phosphorylation of the mitogen-activated protein (MAP) kinase ERK which has been shown to play a role in pathological angiogenesis (19). Thus, the apparent discrepancy of opposing SPARC functions, i.e., growth inhibition of ECs and stimulation of angiogenesis, has existed. The aim of this study was to clarify the effect of VEGF on the expression of SPARC in human vascular ECs, and to explain roles of SPARC in these processes.

\section{MATERIALS AND METHODS}

Reagents. The reagents used and their source were the following: SB203580 and SB202190 (p38-specific inhibitors) and PD098059 (MAP kinase kinase (MEK)-specific inhibitor), from Calbiochem (La Jolla, CA); RPMI 1640 and MCDB131, from Gibco/BRL (Grand Island, NY); hydrocortisone, collagenase, heparin, and bisbenzimide, from Sigma (St. Louis, MO); fetal bovine serum (FBS), from Sera-Lab (Sussex, UK); endothelial cell growth factor (ECGF), from Roche diagnostics GmbH (Mannheim, Germany); bovine serum albumin 
(BSA), from Acros Organics (NJ); peroxidase-conjugated swine anti-rabbit IgG (1:1000), from Dako (Copenhagen, Denmark); VEGF, from R\&D System (Abingdon, UK); immobilon-P (PVDF) membrane, from Millipore (Bedford, MA); Instra-Pure RNA purification kit, from Eurogentic (Liège, Belgium); osteonectin ELISA kit, from Takara (Tokyo, Japan); the enhanced chemiluminescence (ECL) assay kit, from Amersham (Buckinghamshire, UK); reverse transcription-polymerase chain reaction (RT-PCR) kit, from Perkin-Elmer (Foster, CA). SPARC polyclonal antibody was a gift from Dr. Larry Fisher (NIDR, NIH, Bethesda, MD).

Cell and cell culture. HMEC-1 cell line (SV-40 T antigen-transformed human microvascular ECs (20)) was provided by Dr. W. Ades (Biological Products Branch, Centers for Disease Control, Atlanta, GA). The cells were maintained in MCDB131 supplemented with $10 \% \mathrm{FBS}$ and $1 \mu \mathrm{g} / \mathrm{ml}$ hydrocortisone, and routinely subcultured by trypsinization. Human umbilical vein ECs (HUVECs) were prepared according to the guide line of the University of Liège (Belgium) and to the method described previously $(21,22)$. Briefly, they were isolated using $0.1 \%$ collagenase and cultured on $0.2 \%$ gelatin-coated dishes in RPMI 1640 supplemented with $10 \mathrm{mM}$ Hepes, 5\% heat-decomplemented pooled human serum, 5\% FBS, $20 \mu \mathrm{g} / \mathrm{ml}$ ECGF, and $50 \mu \mathrm{g} / \mathrm{ml}$ heparin. We define these culture conditions as "complete medium." HUVECs were always used at the second passage. They showed typical cobblestone morphology when grown to confluence, and were tested to be positive for von Wille-brand factor antigen as an EC-specific marker.

Assay for SPARC induction by VEGF. HUVECs were seeded in gelatin-coated 24-well plates at a density of $1 \times$ $10^{5}$ cells/well in the complete medium, cultured for 2 days at $37^{\circ} \mathrm{C}$ in a humidified atmosphere until confluent, washed twice with serum-free MCDB131, and then preincubated in MCDB131 containing 0.1\% BSA for $6 \mathrm{~h}$. VEGF was then introduced into some of the wells and incubation was continued for $24 \mathrm{~h}$. The conditioned medium (CM) was analysed by ELISA. HMEC- 1 cells were seeded into 24-well plates at a density of $2 \times 10^{5}$ cells/well and cultured overnight in MCDB131 supplemented with 0.5\% FBS. Hydrocortisone was excluded. The cells were washed twice with serum-free MCDB131 and then preincubated in the serum-free medium for 24 h. They were then cultured in MCDB131 supplemented with VEGF for $48 \mathrm{~h}$. The CM was reversed for Western blot analysis.

Preparation of CM for Western blotting. Proteins in CM were precipitated by adding 3 volumes of precooled ethanol for each volume of $\mathrm{CM}$, and the mixture was stored at $-20^{\circ} \mathrm{C}$ for $16-20 \mathrm{~h}$. Proteins were separated by centrifuging at $4^{\circ} \mathrm{C}$ and $15,000 \mathrm{~g}$ for $30 \mathrm{~min}$. The dry precipitate was dissolved in phosphate-buffered saline or mixed directly with sodium dodecyl sulphate (SDS)-sample buffer ( $0.5 \mathrm{mM}$ Tris-HCl (pH 6.8) containing $1 \%$ SDS, $10 \%$ 2-mercapto-ethanol, and $0.2 \%$ glycerol). Cultures were normalized for Western blotting based on DNA content (1.5 $\mu \mathrm{g}$-DNA/lane; approximately $10 \mu \mathrm{g}$-protein/lane). DNA content was measured using bisbenzimide, and protein concentration was determined with a Bio-Rad protein assay kit using BSA as the standard.

Western blotting. Western blotting was carried out according to the method reported previously $(15,23,24)$. Briefly, the proteins were separated by $1 \%$ SDS-contained $10 \%$ polyacrylamide gel electrophoresis (SDSPAGE). The separated proteins were transferred onto an Immobilon-P (PVDF) membrane at a constant voltage of 50 volts for $2 \mathrm{~h}$ in a Bio-Rad transblot apparatus. Anti-SPARC polyclonal antibodies (1:2000) were used as a primary antibody; and peroxidase-conjugated swine anti-rabbit IgG (1:1000) as the secondary antibody. SPARC bands were visualized by use of an ECL assay kit.

ELISA. Collected CM were directly assayed with the osteonectin ELISA kit. Assays were done according to the manufacturer's protocol with some modifications. This assay kit gives linear results for concentrations from 0-10 $\mathrm{ng} / \mathrm{ml}$, and has a sensitivity of $0.3 \mathrm{ng} / \mathrm{ml}$.

$R T$-PCR. ECs were serum-starved for $48 \mathrm{~h}$. Some cells were cultured with $25 \mathrm{ng} / \mathrm{ml}$ of VEGF for $18 \mathrm{~h}$ in the serum-free medium, whereas others were cultured without VEGF. Total RNA was extracted by use of the InstraPure RNA purification kit. Total RNA (10 ng) was then reverse-transcribed and amplified with the primers specific for SPARC by using an RT-PCR kit. The PCR products were separated by $2 \%$ agarose gel and visualized by staining with ethidium bromide. Sequence of primers used in this study were as follows: for SPARC (final product of 936 base pairs (bp)), 5'-CTG CAG ACC ATG AGG GCC TGG ATC-3' (upstream) and 5'-CTG CAG GGA GTG GAT TTA GAT CAC AAG-3' (downstream); for 28S rRNA (final product of 212 bp), 5'-GTT CAC CCA CTA ATA GGG AAC GTG A-3' (upstream) and 5'-GGA TTC TGA CTT AGA GGC GTT CAG T-3' (downstream). Underlined sequence indicate additional oligonucleotides for the PstI recognition site. The product of PCR obtained with the above primers was sequenced to verify that the PCR with these primers specifically amplified the respective genes. The 28S rRNA primer set was a gift from Dr. Charles A. Lambert (Lab. Connect. Tissues Biol., Univ. of Liège, Belgium). PCR cycles were carried out as follows: $94^{\circ} \mathrm{C}$ for $30 \mathrm{~s}$, 
$56^{\circ} \mathrm{C}$ for $30 \mathrm{~s}$, and $72^{\circ} \mathrm{C}$ for $30 \mathrm{~s} \mathrm{(28} \mathrm{cycles)} \mathrm{for} \mathrm{SPARC;} \mathrm{and} 94^{\circ} \mathrm{C}$ for $30 \mathrm{~s}, 66^{\circ} \mathrm{C}$ for $15 \mathrm{~s}, 72^{\circ} \mathrm{C}$ for $30 \mathrm{~s}(19$ cycles) for $28 \mathrm{~S}$ rRNA.

FIG. 1. Induction of SPARC production from HUVECs by VEGF. The confluent HUVECs were serum-starved for $6 \mathrm{~h}$ and then treated with 0-25 $\mathrm{ng} / \mathrm{ml}$ of VEGF for $24 \mathrm{~h}$. SPARC concentration in CM was determined by ELISA. Data was expressed from-triplicate assay. ${ }^{*} P<0.05 ; * * P<0.01$.

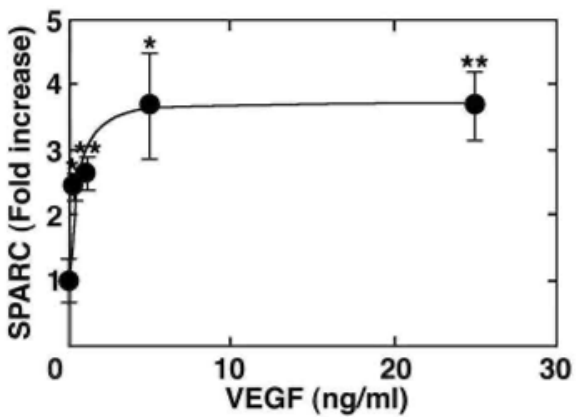

\section{RESULTS}

Effect of VEGF on production of SPARC protein and mRNA. We examined the dose-dependency of SPARC expression elicited by VEGF. HUVECs were preincubated in serum-deprived medium for $24 \mathrm{~h}$ and then incubated for $48 \mathrm{~h}$ with VEGF in the serum-free medium. The production of SPARC protein was dosedependently stimulated by VEGF and reached a plateau at $5 \mathrm{ng} / \mathrm{ml}$ (Fig. 1), whereas the cell number was not affected by addition of VEGF under such a serum-free condition (data not shown). Quite similar effects were obtained when HMEC-1 cells were treated with VEGF (Fig. 2A). When HMEC-1 cells were serum-starved for $48 \mathrm{~h}$ and then treated with $25 \mathrm{ng} / \mathrm{ml}$ of VEGF for $18 \mathrm{~h}$, the steady-state level of SPARC mRNA expression was increased (Fig. 2B). These results suggest that VEGF acts on SPARC production at the pre-translational stage, such as by increasing mRNA stability and/or the level of transcription. Due to the limitations on cell activity in serum-free medium, we could maintain HMEC-1 cells in the serum-starved condition for only a maximum of 72 h. Although we detected faint levels of accumulated SPARC protein by Western blotting during the 48-h incubation under nonstimulus conditions after the 24-h serum starvation, there was no detectable SPARC mRNA expression when the cells were subjected to the 18-h incubation without VEGF (as the control for VEGF treatment for $18 \mathrm{~h}$ ) after $48 \mathrm{~h}$ of serum starvation (data not shown). Due to a relatively long half-life of SPARC mRNA (25), we might have detected faint levels of SPARC protein after serum-starvation. Alternatively, this weak protein expression may indicate that SPARC was able to be slowly released from the intracellular pool after serum-starvation (26).

FIG. 2. Induction of SPARC production from HMEC-1 cells by VEGF. (A) Western blot analysis. HMEC-1 cells were serum-starved for $24 \mathrm{~h}$ and then treated with 0-25 $\mathrm{ng} / \mathrm{ml}$ of VEGF for $48 \mathrm{~h}$. The CM was concentrated and analyzed by Western blotting. Results were shown by densitometric analysis. Inset, original blot. (B) RT-PCR. HMEC-1 cells were serum-starved for $48 \mathrm{~h}$ and then treated with (+) or without (-) $25 \mathrm{ng} / \mathrm{ml}$ of VEGF for $18 \mathrm{~h}$. Total RNA (10 ng) was extracted, reverse-transcribed, and amplified with specific primers. Representative results were shown from at least two independent experiments.

A

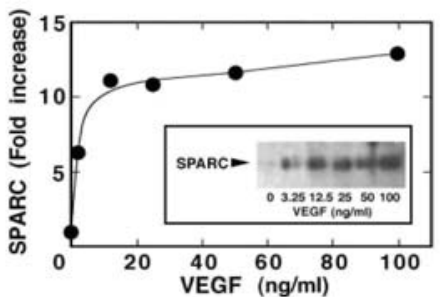

B

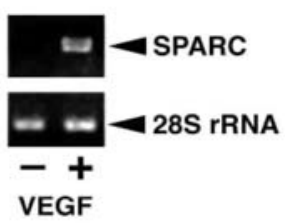


FIG. 3. Inhibition of VEGF-induced SPARC production by MAP-kinase-specific inhibitors analyzed by Western blotting. HMEC-1 cells were serum-starved for $24 \mathrm{~h}$ and then cultured for $48 \mathrm{~h}$ and without the MAP-kinase inhibitors SB202190 or SB203580 (for p38), and PD098059 (for MEK). (A) Western blot; (B) densitometry of the blot. Representative results were shown from at least two independent experiments.

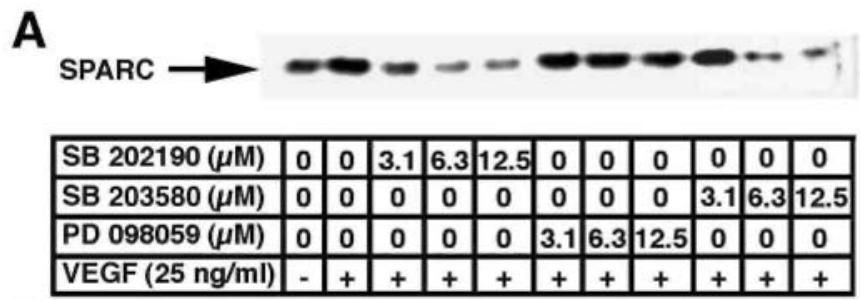

B

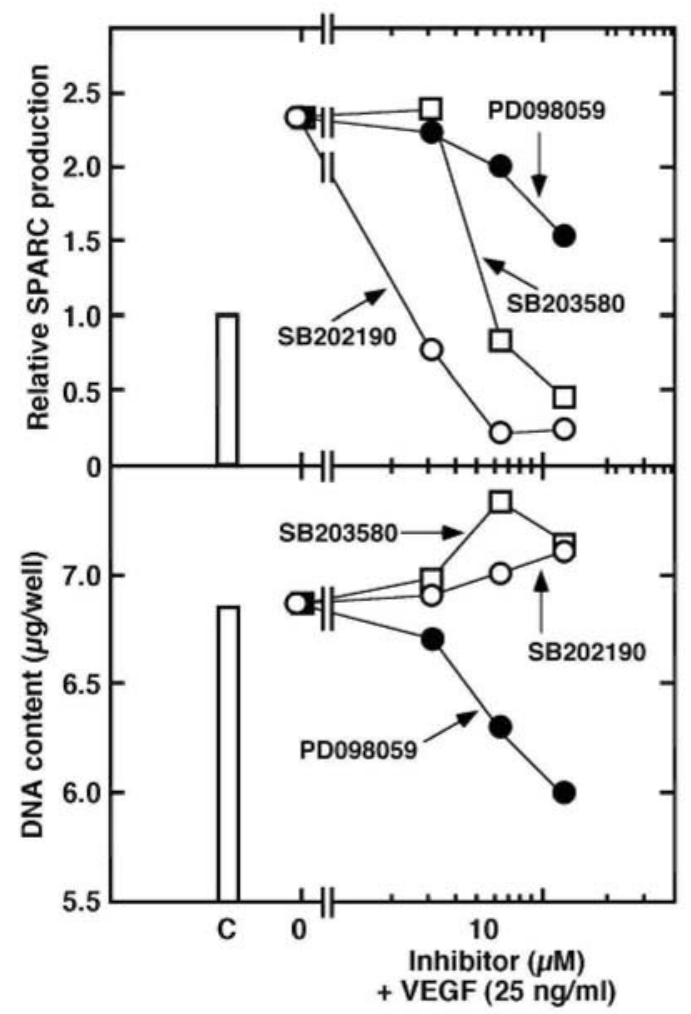


FIG. 4.Two possible roles of SPARC in VEGF signaling in ECs with respect to tumor progression. *Reference numbers; $\$$ Data described in this study.

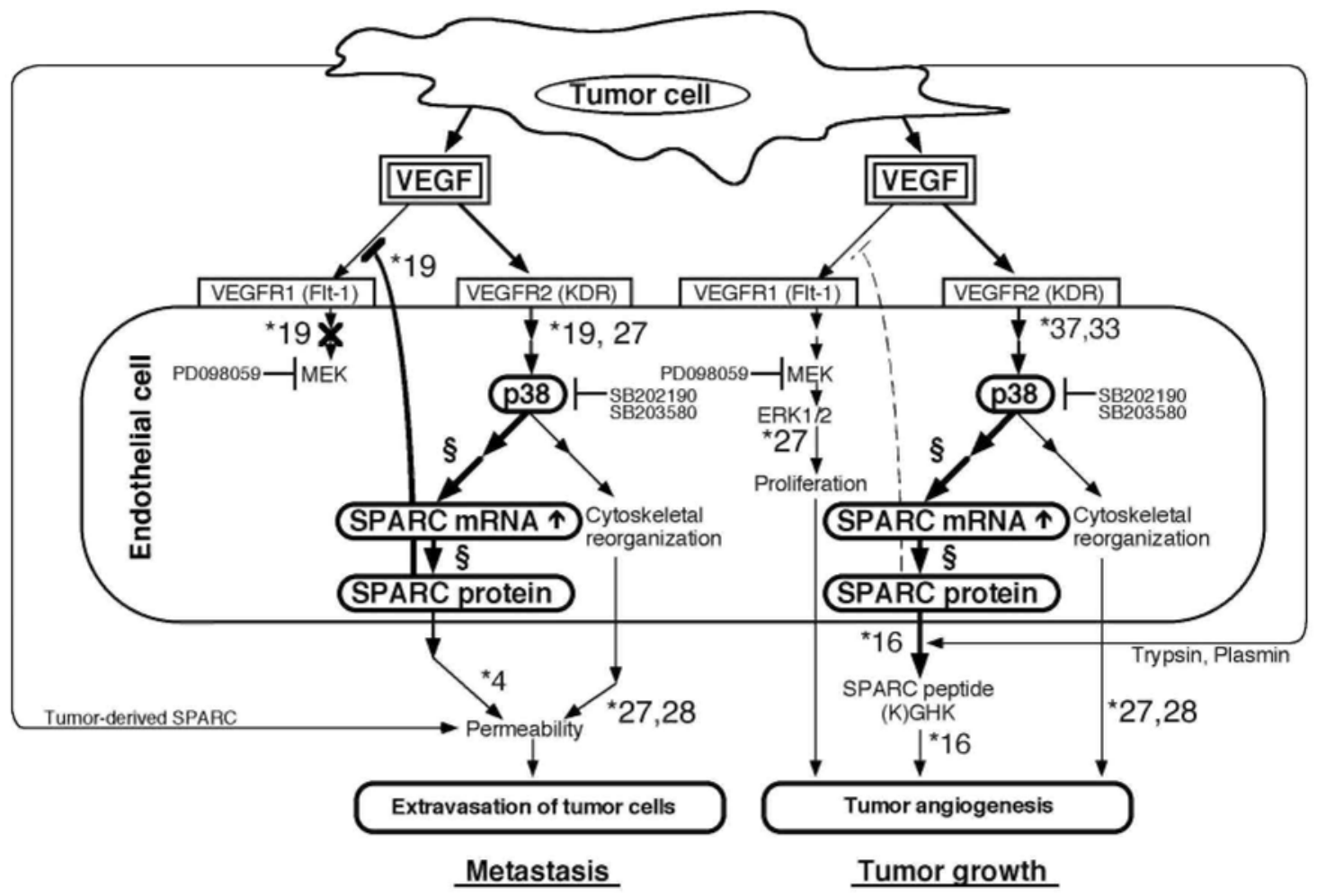

VEGF induces SPARC production through the activation of p38. Two MAP kinases, ERK1/2 and p38, have previously been shown to be involved in the VEGF signal transduction pathway in vascular ECs $(27,28)$. To test the contribution of such MAP kinases to SPARC induction by VEGF, we examined the effect of PD098059 (an inhibitor of MEK, which is an activator of ERK1/2) and SB202190 (an inhibitor of p38) on the induction. SB202190 suppressed the VEGF-induced production of SPARC protein (Figs. 3A and 3B), while it did not suppress the growth of ECs (Fig. 3B). On the other hand, PD098059 less effective for the production of SPARC. SB203580, which is another type of inhibitor of p38 MAP kinase, suppressed SPARC production in a manner similar to that of SB202190 and it did not suppress the growth of ECs. These data suggest that p38 MAP kinase plays a major role in the VEGF signal transduction pathway, which finally stimulates SPARC production.

\section{DISCUSSION}

High levels of SPARC expression have been observed in several tumor cells (9-15). Down-regulation of SPARC production by transfection with antisense oligonucleotides for SPARC mRNA abolished tumorigenicity of human melanoma cells in nude mice (29). Contrary to these reports, over-expression of SPARC by transfection of its expression vector in the ovarian cancer cell line also diminished their tumorigenicity (30). Thus, it is controversial whether SPARC supports the malignant phenotype of tumour cells or vice versa. We have found that SPARC was frequently observed in renal cell carcinomas (18), which are well known to be hypervascular neoplasm over-expressing VEGF. Especially, ECs adjacent to such tumors expressed SPARC. Despite the facts that SPARC-derived peptide induces angiogenesis, SPARC has been reported to inhibit the VEGF mitogenic effect by inhibiting intracellular signaling. To resolve such a discrepancy, we examined the effect of VEGF on SPARC production in vascular ECs. Our experimental results showed for the first time that VEGF dosedependently stimulated SPARC production by both HMEC-1 cells and HUVECs.

KDR/Fllk-1 and Filt-1 are receptor tyrosine kinases for VEGF. Kupprion et al. (19) recently showed that SPARC directly bound to VEGF and repressed the mitogenic activity of this growth factor by inhibiting Flt-1 receptor phosphorylation but found that KDR was not affected by SPARC. ERK1/2 phosphorylation was also inhibited by exogenous SPARC, suggesting that ERK1/2 contributes to the modulation of VEGF function downstream of Fit-1 receptor signal. Furthermore, SU5416, an inhibitor specific for KDR/Flk-1 tyrosine kinase has shown to reduce vascular density accompanied by the inhibition of tumor invasion and SPARC expression in glioma (31). As Rousseau et al. (27) have demonstrated, although VEGF was able to activate two MAP kinases, p38 and ERK, up-regulation of chemotaxis of vascular ECs by VEGF was mediated by p38 but not by ERK 
MAP kinase, which findings were confirmed by Xiong et al. (32). The com-bined results suggest that SPARC is a key regulator for the cellular activity of ECs leading to proliferation and providing barrier function, as summarized in Fig. 3.

Peptide (K)GHK, the fragment produced when SPARC is digested by plasmin or trypsin, is known to promote angiogenesis in vitro and in vivo (33). Intact SPARC did not show angiogenic activity in vivo, but induced production of plasminogen activator inhibitor-1 $(2,34)$ and blocked migration of ECs stimulated by basic fibroblast growth factor (bFGF) (35). These effects contribute angiogenesis. Accordingly, we proposed two possible roles of SPARC in VEGF signaling in ECs: (i) SPARC in its intact form inhibits VEGF-induced proliferation but stimulates increased permeability of the EC barrier for extravasation of tumor cells, (ii) SPARC is immediately degraded after its secretion, generating the (K)GHK peptide, which is associated with tumor growth through the induction of tumor angiogenesis (Fig. 4). This idea is supported by the report from Ledda et al, showing that multiple bands of SPARC, resulting from deglycosilation and proteolysis, were detected on Western blots of human melanoma cells (11). We have also found such bands in the case of mouse metastatic B16 melanoma cells (15). Thus, under pathological conditions, an imbalance between SPARC and proteinase levels in favour of the latter might cause an increased amount of SPARC-derived peptide and thus contribute to angiogenesis. In fact, trypsin has been frequently detected in malignant cancers $(23,36)$ and ECs (37). Variation in the balance between the amount of SPARC production and quantity of (K)GHK peptide formation by its degradation may thus be responsible for the apparent discrepancy of SPARC effects on tumor angiogenesis.

\section{ACKNOWLEDGMENTS}

We would like to thank Dr. Larry Fisher (National Institute for Dental Research, National Institute for Health, Bethesda, MD) for providing the anti-SPARC polyclonal antibody, Dr. E. W. Ades (Biological Products Branch, Centers for Disease Control, Atlanta, GA) for providing HMEC-1 cells, and Dr. Charles A. Lambert (Laboratory of Connective Tissues Biology, University of Liège, Belgium) for providing the 28S rRNA primer set. This work was supported in part by a Grant-in-Aid from the Ministry of Education, Science, Sports, and Culture of Japan (to Y.K.) and by the Public Trust Haraguchi Memorial Cancer Research Fund, Japan (to Y.N.).

\section{REFERENCES}

1. Murphy-Ullrich, J. E., Lane, T. F., Pallero, M. A., and Sage, E. H. (1995) J. Cell. Biochem. 5705, 341-350.

2. Lane, T. F., Iruela-Arispe, M. L., and Sage, E. H. (1992) J. Biol. Chem. 267, 16736-16745.

3. Kamihagi, K., Katayama, M., Ouchi, R., and Kato, I. (1994) Biochem. Biophys. Res. Commun. 200, $423-428$.

4. Goldblum, S. E., Ding, X., Funk, S. E., and Sage, E. H. (1994) Proc. Natl. Acad. Sci. USA 91, 3448-3452.

5. Shankavaram, U. T., DeWitt, D. L., Funk, S. E., Sage, E. H., and Wahl, L. M. (1997) J. Cell Physiol. 173, $327-334$.

6. Gilles, C, Bassuk, J. A., Pulyaeva, H., Sage, E. H., Foidart, J.-M., and Thompson, E. W. (1998) Cancer Res. 58, $5529-5536$.

7. Kato, Y., Sakai, N, Baba, M., Kaneko, S., Kondo, K., Kubota, Y., Yao, M., Shuin, T., Saito, S., Koshika, S., Kawase, T., Miyagi, Y., Aoki, I., and Nagashima, Y. (1999) Invasion Metastasis 18, 105-114.

8. Jacob, K., Webber, M., Benayahu, D., and Kleinman, H. K. (1999) Cancer Res. 59, 4453-4457.

9. Porte, H., Chastre, E., Prevot, S., Nordlinger, B., Empereur, S., Basset, P., Chambon, P., and Gespach, C. (1995) Int. J. Cancer 64, 70-75.

10. Bellahcene, A., and Castronovo, V. (1995) Am. J. Pathol. 146, 95-100.

11. Ledda, F., Bravo, A. I., Adris, S., Bover, L., Mordoh, J., and Podhajcer, O. L. (1997) J. Invest. Dermatol. 108, $210-214$.

12. Porte, H., Triboulet, J. P., Kotelevets, L., Carrat, F., Prevot, S., Nordlinger, B., DiGioia, Y., Wurtz, A., Comoglio, P., Gespach, C, and Chastre, E. (1998) Clin. Cancer Res. 4, 1375-1382. 
Published in: Biochemical \& Biophysical Research Communications (2001), vol. 287, iss. 2, pp. 422-6

Status: Postprint (Author's version)

14. Rempel, S. A., Ge, S., and Gutierrez, J. A. (1999) Clin. Cancer Res. 5, 237-241.

15. Kato, Y., Frankenne, F., Noël, A., Sakai, N., Nagashima, Y., Koshika, S., Miyazaki, K, and Foidart, J.-M. (2000) Pathol. Oncol. Res. 6, 24-26.

16. Lane, T. F., Iruela-Arispe, M. L., Johnson, R. S., and Sage, E. H. (1994) J. Cell Biol. 125, 929-943.

17. Paley, P. J., Goff, B. A., Gown, A. M., Greer, B. E., and Sage, E. H. (2000) Gynecol. Oncol. 78, 336-341.

18. Sakai, N, Baba, M., Nagashima, Y., Kato, Y., Hirai, K, Kondo, K., Kobayashi, K, Yoshida, M., Kaneko, S., Kishida, T., Kawakami, S., Hosaka, M., Inayama, Y., and Yao, M. (2001) Hum. Pathol, in press.

19. Kupprion, C, Motamed, K, and Sage, E. H. (1998). J. Biol. Chem. 273, 29635-29640.

20. Ades, E. W., Candal, F. J., Swerlick, R. A., George, V. G., Summers, S., Bosse, D. C, and Lawley, T. J. (1992) J. Invest. Dermatol. 99, 683-690.

21. Jaffe, E. A., Nachman, R. L., Becker, C. G., and Minick, C. R. (1973) J. Clin. Invest. 52, 2745-2756.

22. Lewalle, J.-M., Cataldo, D., Bajou, K, Lambert, C. A., and Foidart, J.-M. (1998) Clin. Exp. Metastasis 16, 21-29.

23. Kato, Y., Nagashima, Y., Koshikawa, N, Miyagi, Y., Yasumitsu, H., and Miyazaki, K. (1998) Eur. J. Cancer 34, $1117-1123$.

24. Baba, Y., Tsukuda, M., Mochimatsu, I., Furukawa, S., Kagata, H., Nagashima, Y., Sakai, N, Koshika, S., Imoto, M., and Kato, Y. (2000) Clin. Exp. Metastasis 18, 273-279.

25. Wrana, J. L., Overall, C. M., and Sodek, J. (1991) Eur. J. Biochem. 197, 519-528.

26. Gooden, M. D., Vernon, R. B., Bassuk, J. A., and Sage, E. H. (1999) J. Cell. Biochem. 74, 152-167.

27. Rousseau, S., Houle, F., Landry, J., and Huot, J. (1997) Oncogene 15, 2169-2177.

28. Zeng, H, Dvorak, H. F., and Mukhopadhyay, D. (2001) J. Biol. Chem. 276, 26969-26979.

29. Ledda, M. F., Adris, S., Bravo, A. I., Kairiyama, C, Bover, L., Chernajovsky, Y., Mordoh, J., and Podhajcer, O. L. (1997) Nature Med. $3,171-176$

30. Mok, S. C, Chan, W. Y., Wong, K. K, Muto, M. G., and Berko-witz, R. S. (1996) Oncogene 12, 1895-1901.

31. Vajkoczy, P., Menger, M. D., Goldbrunner, R., Ge, S., Fong, T. A., Vollmar, B., Schilling, L., Ullrich, A., Hirth, K. P., Tonn, J. C, Schmiedek, P., and Rempel, S. A. (2000) Int. J. Cancer 87, 261-268.

32. Xiong, S., Grijalva, R., Zhang, L., Nguyen, N. T., Pisters, P. W., Pollock, R. E., and Yu, D. (2001) Cancer Res. 61, $1727-1732$.

33. Iruela-Arispe, M. L., Lane, T. F., Redmond, D., Reilly, M., Bo-lender, R. P., Kavanagh, T. J., and Sage, E. H. (1995) Mol. Biol. Cell 6, 327-343.

34. Hasselaar, P., Loskutoff, D. J., Sawdey, M., and Sage, E. H. (1991) J. Biol. Chem. 266, 13178-13184.

35. Hasselaar, P., and Sage, E. H. (1992) J. Cell. Biochem. 49, 272-283.

36. Hirahara, F., Miyagi, Y., Miyagi, E., Yasumitsu, H, Koshikawa, N., Nagashima, Y., Kitamura, H, Minaguchi, H, Umeda, M., and Miyazaki, K. (1995) Int. J. Cancer 63, 176-181.

37. Koshikawa, N, Nagashima, Y., Miyagi, Y., Mizushima, H, Ya-noma, S., Yasumitsu, H, and Miyazaki, K. (1997) FEBS Lett. 409, 442448. 